\title{
Markers of inflammation and tolerance development in allergic proctocolitis
}

\author{
Hikmet T. Nacaroglu, M.D. ${ }^{a}$, Semiha Bahceci Erdem, M.D. ${ }^{b}$, Ersin Durgun, M.D. ${ }^{b}$, \\ Sait Karaman, M.D. ${ }^{b}$, Cahit Baris Erdur, M.D. ${ }^{b}$, Canan S. Unsal Karkıner, M.D. ${ }^{b}$ and \\ Demet Can, M.D. Prof. ${ }^{b}$
}

\begin{abstract}
Background. Today, as a result of an increase in the frequency of food protein-induced allergic proctocolitis (FPIAP), there is a need for studies not only to enlighten the pathophysiology of the disease but also to determine simple, non-invasive markers in both diagnosis, and evaluation of the development of tolerance. No study has been found in the literature about the place of neutrophil/lymphocyte ratio (NLR) and mean platelet volume (MPV), which are easy to calculate and non-invasive markers.

Objectives. The purpose is to determine the relation between NLR and MPV with the diagnosis and development of tolerance in children with FPIAP.

Methods. In this retrospective cross-sectional study, clinical, demographic symptoms and laboratory findings of patients, monitored with FPIAP diagnosis in allergy and gastroenterology clinics, were acquired from the patient record system. Hemogram values at the time of diagnosis were compared with the values of healthy children of the same age and gender. Results. Among 59 patients diagnosed with FPIAP, males constitute $47.4 \%$ and females constitute $52.6 \%$. MPV and platelet crit (PCT) values were significantly high when compared to the control group $(n: 67)$ in FPIAP cases $(p<0.001)$. Also, MPV and PCT values were significantly high in non-tolerance developing cases when compared to developing ones $(\mathrm{p}=0.01)$.

Conclusions. Contrary to NLR, MPV and PCT values have been considered to be good markers in predicting prognosis in cases with FPIAP since they are quick, costeffective and easy to calculate. Keywords: Food allergic, protein-induced, proctocolitis, mean platelet volume, inflammation.
\end{abstract}

http:/ / dx.doi.org/10.5546/aap.2018.eng.e1

To cite: Nacaroglu HT, Bahceci Erdem S, Durgun $\mathrm{E}$, et al. Markers of inflammation and tolerance development in allergic proctocolitis. Arch Argent Pediatr 2018;116(1):e1-e7.

\section{E-mail address: \\ Hikmet T.}

Nacaroglu, M.D.:

tekin212@gmail.com

Funding:

None.

Conflict of interest:

None.

Received: 4-26-2016

Accepted: 8-4-2017

\section{INTRODUCTION}

The prevalence of food allergy has increased in recent decades, especially in the pediatric population..$^{1,2}$ According to the World Allergy Organization guidance, food allergy can be IgE-mediated or non-IgE-mediated. ${ }^{3}$ Although the mechanism and pathogenesis of IgE-mediated food allergy is comprehended more clearly, the mechanism and pathogenesis of gastrointestinal food allergies, including food protein-induced allergic proctocolitis (FPIAP) is still not very clear. FPIAP is also one of them. FPIAP starts usually during the first months of the life in otherwise healthy infants. FPIAP is characterized by mucus, blood and foam in the stool. Patients do not experience growth retardation; however, weight gain can be slow. Mild anemia can be rarely seen and sometimes it accompanies hypoalbuminemia. ${ }^{1-4}$

While FPIAP prognosis is generally good, its pathophysiology has not been elucidated yet. Today, as a result of an increase in the frequency of FPIAP, there is a need for studies not only to enlighten the pathophysiology of the disease but also to determine simple and non-invasive markers in both the diagnosis and evaluation of the tolerance development. White blood cell count, neutrophil count, and neutrophil/lymphocyte ratio (NLR) are the markers of systemic inflammation. That the NLR can be a marker of systemic inflammation has been shown in various systemic inflammatory diseases. ${ }^{5,6}$ It has been also shown that platelets contribute to the development of inflammation in various allergic diseases and 
coordinate the transmission of all leucocytes, especially eosinophil and neutrophil, to inflammation area. ${ }^{7}$ Mean platelet volume (MPV) is a value of platelet activation and it is used as a marker in inflammation..$^{8,9}$ No study has been found in the literature about the place of FPIAP of NLR and MPV, which are easy to calculate and non-invasive markers.

The purpose is to determine the relation between NLR and MPV with the diagnosis and development of tolerance in children with FPIAP.

\section{METHODS AND MATERIALS \\ Patients' population}

In this retrospective cross-sectional study, clinical, demographic symptoms and laboratory findings of patients, monitored with FPIAP diagnosis in allergy and gastroenterology clinics, during January 2010 to January 2015, were acquired from the patient record system. Hemograms values at the time of diagnosis were compared with the values of healthy children of the same age and gender, obtained from the records of healthy cases in which anemia was not detected. Since iron prophylaxis is routinely initiated in infants in our country, routine screening of hemogram is required in cases of healthy child policlinic follow-up.

Furthermore, cases developing and not developing tolerance were also compared between each other by the stated parameters. Patients with missing data in their files, patients for whom FPIAP diagnosis could not be verified via challenge following elimination, patients with infections leading to bloody diarrhea, patients with an anal fissure, perianal dermatitis/excoriations, invagination, coagulation defects, necrotizing enterocolitis, inflammatory bowel diseases, vitamin $\mathrm{K}$ deficiency and immunodeficiency were excluded. This study was approved by the local ethics committee of our hospital (2015/18-08).

\section{FPIAP definition}

In the study, the diagnosis of allergic proctocolitis is defined according to the criteria suggested in the European Academy of Allergy and Clinical Immunology (EAACI) food allergy and anaphylaxis guidelines and the expert panel report (Guidelines for the Diagnosis and Management of Food Allergy in the United States). These guidelines suggest the use of "history, improvement of symptoms by eliminating the offending food, recurrence of symptoms following oral food challenge" ${ }^{10}$

\section{Oral food challenge (OFC) and age of resolution}

Milk and milk products were eliminated from the diet of the mothers for breastfed infants. The formula was replaced with extensively hydrolyzed formula (eHF) or aminoacid-based formula for formula fed infants. In infants, for whom clinical improvement was observed within 72-96 hours (complete resolution in the stool sample can take 1 week if there is significant blood), the offending food was restarted in the $3^{\text {rd }}$ week. The patient was diagnosed with FPIAP if the offending food caused rectal bleeding, diarrhea, and mucus again. If there was no response with this diet, egg and wheat products were eliminated from the diet of the mother or the infant to be started again 3 weeks after. Elementary diet was preferred in case there was no response to milk, egg and wheat products in patients with multiple food allergies. Foods were started one by one after all the symptoms were overcome with elimination diet and in this manner, the offending food was tried to be determined. Patients who passed OFC during the follow-up or who completely tolerated the food at home were accepted as treated. OFC was repeated in our clinic with 6-month intervals. Challenge protocol was carried out based on FA work group report and EAACI position paper. ${ }^{11,12}$ The IgE-mediated supplement was administered every 15 minutes in increasing doses of $0.1 \mathrm{ml}$, $1.0 \mathrm{ml}, 3.0 \mathrm{ml}, 10 \mathrm{ml}, 30 \mathrm{ml}, 50 \mathrm{ml}$ and $100 \mathrm{ml}$ due to the allergic disease. Patients for whom no reaction was observed during OFC continue to take food at home and the families were warned regarding late phase reactions. Mothers of some children were tested at home whether there was any improvement or not. As a result, the diet was terminated if the symptoms were not observed again and the patient follow-up was discontinued. Diet was continued in patients for whom symptoms restarted and $\mathrm{OFC}$ was repeated every 6 months.

\section{Statistical analysis}

In this study, statistical analyses were performed usingNCSS (Number Cruncher Statistical System) 2007 Statistical Software (Utah, USA) package program. For the evaluation of the data, in addition to descriptive statistical methods (mean, standard deviation), the independent t-test was used in the comparison of binary groups and the chi-square test was used in the comparison of qualitative data. For the differential diagnosis of proctocolitis, the area under the ROC curve was 
calculated, Sensitivity, Specificity, PPV, NPV and $\mathrm{LR}(+)$ values were measured. The results were evaluated at the significance level of $\mathrm{p}<0.05$ and in the confidence interval of $95 \%$.

\section{RESULTS}

Among 59 patients diagnosed with FPIAP, males constitute $47.4 \%$ and females constitute $52.6 \%$. The age at the onset of symptoms was
$5.28 \pm 5.0$ months. Milk was the offending food in $78 \%$ of the patients, milk/eggs in $13 \%$ of the patients, and eggs in 5\% of the patients. Mean tolerance development time of the patients was $14.77 \pm 11.98$ months (minimum 3-maximum 66 months). Tolerance developed before the age of 1 year in $40 \%(n=31)$, between the ages of $1-2$ in $27 \%(\mathrm{n}=21)$, between the ages of $2-3$ in $9 \%(\mathrm{n}=7)$ and after the age of 3 in $5 \%(n=4)$ of the patients.

TABLE 1. Comparison of clinical and laboratory characteristics of healthy cases (Group I) and cases with food protein-induced allergic proctocolitis (Group II)

\begin{tabular}{|c|c|c|c|c|c|c|}
\hline & & \multicolumn{2}{|c|}{ Group I n= 67} & \multicolumn{2}{|c|}{ Group II n= 59} & $p$ \\
\hline \multicolumn{2}{|c|}{ Age at the onset of symptoms (month) } & \multicolumn{2}{|c|}{$6.09 \pm 2.66$} & \multicolumn{2}{|c|}{$5.28 \pm 5.06$} & 0.255 \\
\hline Gender & $\begin{array}{l}\text { Male } \\
\text { Female }\end{array}$ & & $\begin{array}{l}41.79 \% \\
58.21 \%\end{array}$ & & $\begin{array}{l}52.54 \% \\
47.46 \%\end{array}$ & 0.227 \\
\hline \multicolumn{2}{|c|}{ White blood cell count $\left(\times 10^{3} / \mu \mathrm{L}\right)$} & \multicolumn{2}{|c|}{$11 \pm 7.3$} & \multicolumn{2}{|c|}{$9.9 \pm 3.7$} & 0.303 \\
\hline \multicolumn{2}{|c|}{ Lymphocyte percentage } & \multicolumn{2}{|c|}{$59.4 \pm 12.2$} & \multicolumn{2}{|c|}{$58.9 \pm 13.8$} & 0.815 \\
\hline \multicolumn{2}{|c|}{ Absolute lymphocyte count $\left(\times 10^{3} / \mu \mathrm{L}\right)$} & \multicolumn{2}{|c|}{$5.9 \pm 1.7$} & \multicolumn{2}{|c|}{$5.9 \pm 3.0$} & 0.927 \\
\hline \multicolumn{2}{|c|}{ Neutrophil percentage } & \multicolumn{2}{|c|}{$26.3 \pm 13.04$} & \multicolumn{2}{|c|}{$27.7 \pm 14.1$} & 0.585 \\
\hline \multicolumn{2}{|c|}{ Absolute neutrophil count $\left(\times 10^{3} / \mu \mathrm{L}\right)$} & \multicolumn{2}{|c|}{$2.8 \pm 1.9$} & \multicolumn{2}{|c|}{$2.7 \pm 2.0$} & 0.858 \\
\hline \multicolumn{2}{|c|}{ Neutrophil/lymphocyte ratio } & \multicolumn{2}{|c|}{$0.61 \pm 0.78$} & \multicolumn{2}{|c|}{$0.63 \pm 0.87$} & 0.883 \\
\hline \multicolumn{2}{|c|}{ Hemoglobin (g/dl) } & \multicolumn{2}{|c|}{$11.8 \pm 0.6$} & \multicolumn{2}{|c|}{$11.2 \pm 1.1$} & 0.0001 \\
\hline \multicolumn{2}{|c|}{ Platelet count $\left(\times 10^{3} / \mu \mathrm{L}\right)$} & \multicolumn{2}{|c|}{$382 \pm 941$} & \multicolumn{2}{|c|}{$374 \pm 1138$} & 0.697 \\
\hline \multicolumn{2}{|c|}{$\operatorname{MPV}(\mathrm{fl})$} & \multicolumn{2}{|c|}{$6.87 \pm 1.3$} & \multicolumn{2}{|c|}{$8.29 \pm 1$} & 0.0001 \\
\hline \multicolumn{2}{|l|}{ РCT $\%$} & \multicolumn{2}{|c|}{$0.26 \pm 0.08$} & \multicolumn{2}{|c|}{$0.31 \pm 0.07$} & 0.0001 \\
\hline \multicolumn{2}{|l|}{ PDW $\%$} & & \pm 1.5 & 15.6 & \pm 1.1 & 0.0001 \\
\hline Eosinop & & & 4.7 & 4.6 & $=4.2$ & 0.801 \\
\hline Eosinop & & & +684 & 418 & $=353$ & 0.662 \\
\hline
\end{tabular}

MPV: mean platelet volume; PCT: plateletcrit; PDW: platelet distribution width.

FIGURE 1. Area under de ROC curve for the differential diagnosis of food protein-induced allergic proctocolitis
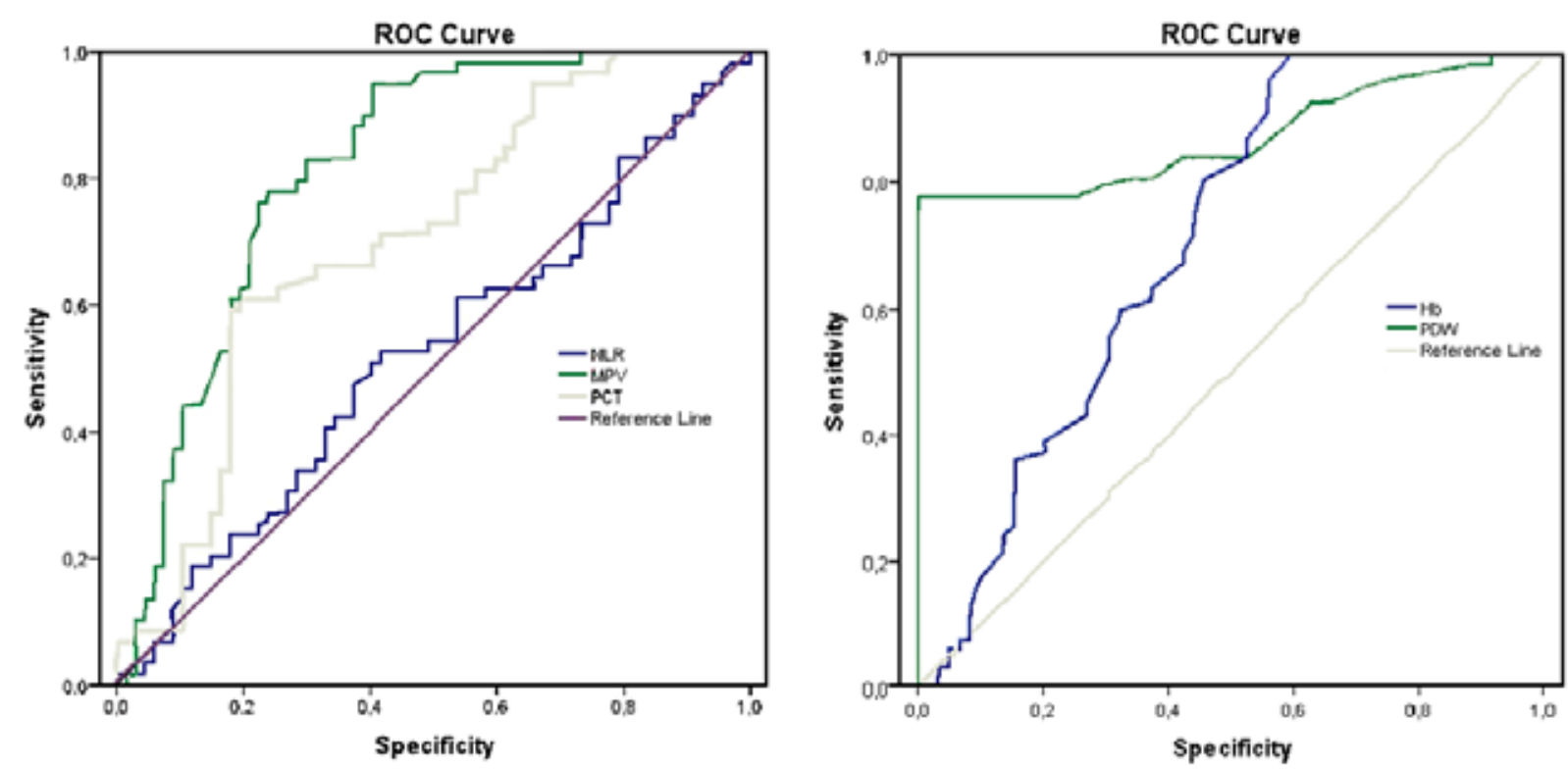
No statistically significant difference was found between white blood cell count, lymphocyte count, neutrophil count, platelet count and mean NLR averages of the cases $(p>0,05)$. MPV and mean plateletcrit (PCT) of the FPIAP group were statistically significantly higher than those of the control group ( $p<0.05)$. Mean values of hemoglobin and platelet distribution width (PDW) of the FPIAP group were statistically significantly lower than those of the control group $(\mathrm{p}<0.05)$ (Table 1).

The area under the ROC curve in the differential diagnosis of FPIAP was found to be 0.703 (0.615 - 0.781) for hemoglobin, 0.816 (0.737 0.880 ) for MPV, 0.703 (0.615 - 0.781) for PCT, 0.869 (0.798 - 0.923) for PDW, and 0.522 (0.431 - 0.612) for NLR (Figure 1). The area under the ROC curve of MPV was statistically significantly higher than hemoglobin, NLR and PCT variables $(\mathrm{p}=0.045$, $\mathrm{p}=0.001, \mathrm{p}=0.028)$. MPV and PCT values of FPIAP cases were significantly higher in the cases not developing tolerance when compared to the cases developing tolerance $(p<0.05)$. No significant difference was found between clinical findings and white blood cell count, neutrophil count and mean NLR of the cases $(p>0.05)$ (Table 2). No correlation was detected between diarrhea, vomiting, abdominal distension, and hospitalization story and OTH, NLR, and platelet count ( $\mathrm{p}>0.05$ ).

\section{DISCUSSION}

In this study conducted to determine inflammatory cells that take part in inflammation and pathogenesis in the cases with FPIAP and to investigate biomarkers that may predict tolerance development. Contrary to NLR, MPV and PCT values were considered to be good markers since they are quick, cost effective and easy to measure. As far as we know, there is no study in the literature that evaluates platelet indices and NLR of inflammation together in the cases with FPIAP.

Mean platelet volume is correlated with platelet function and activation. ${ }^{13}$ Platelet activation that occurs in the process of inflammation can be measured indirectly through MPV. Mean platelet volume alone represents both platelet stimulation and the rate of platelet

TABLE 2. Clinical and laboratory characteristics of cases according to the development of tolerance

\begin{tabular}{|c|c|c|c|c|c|c|}
\hline & & \multicolumn{2}{|c|}{ No tolerance $(n=13)$} & \multicolumn{2}{|c|}{ Tolerance $(n=46)$} & $p$ \\
\hline \multicolumn{2}{|c|}{ Age at the onset of symptoms (month) } & \multicolumn{2}{|c|}{$4.08 \pm 2.22$} & \multicolumn{2}{|c|}{$5.62 \pm 5.58$} & 0.336 \\
\hline Gender & $\begin{array}{l}\text { Male } \\
\text { Female }\end{array}$ & $\begin{array}{l}28 \\
39\end{array}$ & $\begin{array}{l}41.79 \% \\
58.21 \%\end{array}$ & $\begin{array}{l}31 \\
28\end{array}$ & $\begin{array}{l}52.54 \% \\
47.46 \%\end{array}$ & 0.075 \\
\hline Vomiting & $\begin{array}{l}\text { Yes } \\
\text { No }\end{array}$ & $\begin{array}{l}4 \\
9\end{array}$ & $\begin{array}{l}30.77 \% \\
69.23 \%\end{array}$ & $\begin{array}{l}27 \\
19\end{array}$ & $\begin{array}{l}58.70 \% \\
41.30 \%\end{array}$ & 0.374 \\
\hline Diarrhea & $\begin{array}{l}\text { Yes } \\
\text { No }\end{array}$ & $\begin{array}{l}3 \\
10\end{array}$ & $\begin{array}{l}23.08 \% \\
76.92 \%\end{array}$ & $\begin{array}{c}6 \\
40\end{array}$ & $\begin{array}{l}13.04 \% \\
86.96 \%\end{array}$ & 0.481 \\
\hline Abdominal Distention & $\begin{array}{l}\text { Yes } \\
\text { No }\end{array}$ & $\begin{array}{l}11 \\
2\end{array}$ & $\begin{array}{l}84.62 \% \\
15.38 \%\end{array}$ & $\begin{array}{c}42 \\
4\end{array}$ & $\begin{array}{c}91.30 \% \\
8.70 \%\end{array}$ & 0.628 \\
\hline Lethargy & $\begin{array}{l}\text { Yes } \\
\text { No }\end{array}$ & $\begin{array}{l}1 \\
12\end{array}$ & $\begin{array}{c}7.69 \% \\
92.31 \%\end{array}$ & $\begin{array}{c}2 \\
44\end{array}$ & $\begin{array}{c}4.35 \% \\
95.65 \%\end{array}$ & 0.444 \\
\hline Weight Loss & $\begin{array}{l}\text { Yes } \\
\text { No }\end{array}$ & $\begin{array}{l}4 \\
9\end{array}$ & $\begin{array}{l}30.77 \% \\
69.23 \%\end{array}$ & $\begin{array}{c}4 \\
42\end{array}$ & $\begin{array}{l}8.70 \% \\
91.30 \%\end{array}$ & 0.256 \\
\hline \multicolumn{2}{|c|}{ White blood cell count $\left(\times 10^{3} / \mu \mathrm{L}\right)$} & \multicolumn{2}{|c|}{$11 \pm 4.6$} & \multicolumn{2}{|c|}{$9.9 \pm 3.7$} & 0.063 \\
\hline \multicolumn{2}{|c|}{ Lymphocyte percentage } & \multicolumn{2}{|c|}{$65.1 \pm 13.8$} & \multicolumn{2}{|c|}{$57.1 \pm 13.4$} & 0.065 \\
\hline \multicolumn{2}{|c|}{ Absolute lymphocyte count $\left(\times 10^{3} / \mu \mathrm{L}\right)$} & \multicolumn{2}{|c|}{$7.6 \pm 3.6$} & \multicolumn{2}{|c|}{$5.4 \pm 2.6$} & 0.23 \\
\hline \multicolumn{2}{|c|}{ Neutrophil percentage $(\%)$} & \multicolumn{2}{|c|}{$24.9 \pm 13$} & \multicolumn{2}{|c|}{$28.5 \pm 14.4$} & 0.424 \\
\hline \multicolumn{2}{|c|}{ Absolute neutrophil count $\left(\times 10^{3} / \mu \mathrm{L}\right)$} & \multicolumn{2}{|c|}{$2.8 \pm 1.6$} & \multicolumn{2}{|c|}{$2.7 \pm 2.0$} & 0.848 \\
\hline \multicolumn{2}{|c|}{ Neutrophil/lymphocyte ratio } & \multicolumn{2}{|c|}{$0.48 \pm 0.5$} & \multicolumn{2}{|c|}{$0.67 \pm 0.95$} & 0.475 \\
\hline Hemoglobin (g/dl) & & & \pm 1.4 & & \pm 1.1 & 0.228 \\
\hline Platelet count $\left(\times 10^{3} / \mu \mathrm{L}\right.$ & & & 955 & & 912 & 0.067 \\
\hline MPV (fl) & & 8.8 & 0.92 & 8.1 & $=0.96$ & 0.013 \\
\hline РCТ \% & & 0.3 & 0.07 & 0.3 & 0.07 & 0.0001 \\
\hline PDW\% & & 15.6 & \pm 0.38 & 15. & \pm 1.25 & 0.866 \\
\hline Eosinophil percentage & & 3.7 & 2.06 & & $=4.62$ & 0.378 \\
\hline Eosinophil count $(/ \mathrm{mn}$ & & & 211 & & $=386$ & 0.883 \\
\hline
\end{tabular}

MPV: mean platelet volume; PCT: plateletcrit; PDW: platelet distribution width. 
production. ${ }^{14}$ CD62, CD63, GP IIB / IIIA, PF4, and tromboglobulin can be used as markers of platelet activation. ${ }^{15}$ These tests are not routinely used measurements for their high cost and need of specialized equipment. ${ }^{16}$ Measurement of mean platelet volume is a cheap, effective and an easy method that is closely correlated with platelet function and activation. NLR has been used as a marker for inflammation in several diseases because the physiological responses of circulating leukocytes in the human body to stress are an increase in the number of neutrophils and a decrease in the number of lymphocytes. ${ }^{17,18}$ Thus, in our study, we used the MPV measurement to demonstrate activation of platelets which plays a role in gastrointestinal system inflammation and NLR for evaluating the neutrophil-associated inflammation in patients with FPIAP.

The mechanism and pathogenesis of gastrointestinal food allergies are still not properly comprehended. Although an increase in TNF- $\alpha$ response and a decrease in TGF- $\beta$ response have been shown by Scherer and Sampson, ${ }^{19}$ the mechanism is still not clear. It has been shown that, just like IL-4, IFN-gamma released from $\mathrm{T}$ lymphocytes stimulated with a food allergen, cytokines increase intestinal permeability. As a proinflammatory cytokine, the released TNF- $\alpha$ causes neutrophil activation and increases intestinal permeability. ${ }^{20}$ NLR has been associated with some conditions such as chronic inflammation in cardiovascular diseases, hypertension, diabetes mellitus, malignancies, familial mediterranean fever and hepatic cirrhosis, and it has been suggested that NLR has a prognostic importance. ${ }^{5,6}$ In this study, we evaluated white blood cell count, neutrophil count and mean NLR for the demonstration of neutrophilic inflammation considered to take part in pathogenesis in the cases with FPIAP and no statistically significant difference was found when compared to healthy cases ( $p>0.05$ ). Furthermore, no significant difference was found between the cases developing and not developing tolerance $(\mathrm{p}>0.05)$.

Recent studies show that platelets, one of the most important elements of the hemostasis process, also play a role in the development of immune response. ${ }^{7}$ In addition to their already known characteristics, platelets express Inge receptor with both high and low affinities at various levels. ${ }^{21} \mathrm{As}$ a result of this characteristic, they take part in the immune response and also, they can be activated by allergens. Platelets, activated when challenged with allergens, were observed to release mediators such as Platelet Factor 4, $\beta$-tromboglobulin, RANTES, and Thromboxane. ${ }^{7}$ Furthermore, it is seen that platelets also take part in the development of bronchospasm, bronchial hyperreactivity, and remodeling in asthma. Various mediators they include (5-Hydroxytryptamine, leukotrienes, platelet derived hyperreactivity factor, etc.) are seen to be responsible for these processes. ${ }^{7,22,23}$ Platelets also affect the development of inflammation in airways in asthma. They coordinate the transmission of all leucocytes, especially eosinophil and neutrophil, to inflammation area. Furthermore, it is suggested that they may contribute to the development of sensitization with the bond they establish between natural and acquired immunity. ${ }^{7}$ Mean platelet volume is accepted as a marker of platelet activation as a simple methodology. This method has been used to evaluate platelet activation in many diseases. In allergic diseases (chronic urticarial, asthma, allergic rhinitis, etc.), it has been considered as a marker of activation with MPV changes. ${ }^{8,9,24}$ However, as far as we know, the role of platelets in cases with FPIAP has not been investigated, yet. In our study, MPV and PCT values in cases with FPIAP were determined to be significantly high.

FPIAP prognosis is good. Although cases develop tolerance between the ages of 1-3 years, there are not many publications about prognosis. Lake et al. ${ }^{25}$ have stated that all patients develop tolerance after the age of 1 year. Lewinsky et al. ${ }^{26}$ have reported that in $20 \%$ of infants with eosinophilic colitis, the OFC is positive after 1 year. In our study, the development of tolerance takes place at the age of 1 year and before in $40 \%$, between the age of 1-2 years in $27 \%$, between the age of 2-3 years in 9\%, and after the age of 3 year in 5\%. As far as we know, there is no well-defined large group investigating FPIAP prognosis. Likewise, there is no biomarker in use in clinical practice to predict the tolerance development. In our study, while no difference was observed between clinical symptoms, when clinical and laboratory findings of the cases developing and not developing tolerance were compared, MPV and PCT values were significantly higher in the cases not developing tolerance $(p<0.05)$. It is considered that, with these results, the development of tolerance can be predicted to take longer in cases with higher MPV and PCT values. The insufficient number of patients and being 
retrospective are the limitations of this study. Not having a comparison of cytokines such as IL-4, IL-5, IL-6, IL-8, TNF- $\alpha$, INF-gamma, TGF-beta that take part in inflammation, faecal inflammation markers such as faecal calprotectin, faecal eosinophil cationic protein, faecal eosinophil-derived neurotoxin and hemogram parameters is also seen as a limitation. We think that prospective studies and correlation analyses should be carried out about the subject with the markers determined.

\section{CONCLUSION}

Contrary to NLR, MPV and PCT values were considered to be good markers in predicting prognosis in cases with FPIAP since they are quick, cost effective and easy to measure. Prospective studies should be carried out to investigate dependent and independent variables related to this issue in a more comprehensive way.

\section{REFERENCES}

1. Lozinsky AC, Morais MB. Eosinophilic Colitis İn İnfants. J Pediatr (Rios J) 2014;90(1):16-21.

2. Morita H, Nomura I, Matsuda A, et al. Gastrointestinal food allergy in infants. Allergol Int 2013;62(3):297-307.

3. JohanssonSG, Bieber T, Dahl R, etal. Revised nomenclature for allergy for global use: Report of the Nomenclature Review Committee of the World Allergy Organization, October 2003. J Allergy Clin Immunol 2004;113(5):832-6.

4. Nowak-Wegrzyn A. Food protein-induced enterocolitis syndrome and allergic proctocolitis. Allergy Asthma Proc 2015;36(3):172-84.

5. Zhang XY, Simpson JL, Powell H, et al. Full blood count parameters for the detection of asthma inflammatory phenotypes. Clin Exp Allergy 2014;44(9):1137-45.

6. Nacaroğlu HT, İşgüder R, Bent $S$, et al. Can neutrophil/ lymphocyte ratio be a novel biomarker of inflammation in children with asthma. Eur J Inflamm 2016;14(2):109-12.

7. Idzko M, Pitchford S, Page C. Role of platelets in allergic airway inflammation. J Allergy Clin Immunol 2015; 135(6):1416-23.

8. Nacaroğlu HT, İşgüder R, Bahceci SE, et al. Can mean platelet volume be used as a biomarker for asthma? Postepy Dermatol Allergol 2016;33(3):182-7.

9. Doğru M, Aktas A, Ozturkmen S. Mean platelet volume increased in children with asthma. Pediatr Allergy Immunol 2015;26(8):823-6.
10. Boyce JA, Assa'ad A, Burks AW, et al. Guidelines for the diagnosis and management of food allergy in the United States: report of the NIAID-sponsored expert panel.J Allergy Clin Immunol 2010;126 (Suppl 6):S1-58.

11. Nowak-Wegrzyn A, Assa'ad AH, Bahna SL, et al. Work Group Report: oral food challenge testing. J Allergy Clin Immunol 2009;123 (Suppl 6):S365-83.

12. Bindslev-Jensen C, Ballmer-Weber BK, Bengtsson U, et al. Standardization of food challenges in patients with immediate reactions to foods-position paper from the European Academy of Allergology and Clinical Immunology. Allergy 2004;59(7):690-7.

13. Wiwanitkit V. Plateletcrit, mean platelet volume, platelet distribution width: its expected values and correlation with parallel red blood cell parameters. Clin Appl Thromb Hemost 2004;10(2):175-8.

14. Khandekar MM, Khurana AS, DeshmukhSD, et al. Platelet volume indices in patients with coronary artery disease and acute myocardial infarction: an Indian scenario. JClin Pathol 2006;59(2):146-9.

15. Tsiara S, Elisaf M, Jagroop IA, et al. Platelets as predictors of vascular risk: is there a practical index of platelet activity? Clin Appl Thromb Hemost 2003;9(3):177-90.

16. Bath PM, Butterworth RJ. Platelet size: Measurement, physiology and vascular disease. Blood Coagul Fibrinolysis 1996;7(2):157-61.

17. Bhat T, Teli S, Rijal J, et al. Neutrophil to lymphocyte ratio and cardiovascular diseases: a review. Expert Rev Cardiovasc Ther 2013;11(1):55-9.

18. Zahorec R. Ratio of neutrophil to lymphocyte countsRapid and simple parameter of systemic inflammation and stress in critically ill. Bratisl Lek Listy 2001;102(1):5-14.

19. Sicherer SH, Eigennmann PA, Sampson HA. Clinical features of food protein- induced enterocolitis syndrome. J Pediatr 1998;133(2):214-9.

20. Lieberman J, Nowak-Wegrzyn A. Food protein-induced enterocolotis and enteropathies. In: Metcalfe D, Sampson $\mathrm{H}$, Simon R, eds. Food allergy: adverse reactions to foods and food additives. 5th ed. New Delhi: John Wiley \& Sons; 2014.Págs.230-44.

21. Capron M, Joseph $M$. The low affinity receptor for IgE on eosinophils and platelets. Monogr Allergy 1991;29:63-75.

22. Page C, Pitchford S. Platelets and allergic inflammation. Clin Exp Allergy 2014;44(7):901-13.

23. Dürk T, Duerschmied D, Müller T, et al. Production of serotonin by tryptophan hydroxylase 1 and release via platelets contribute to allergic airway inflammation. Am J Respir Crit Care Med 2013;187(5):476-85.

24. Vena GA, Cassano N, Marzano AV, et al. The Role of Platelets in Chronic Urticaria. Int Arch Allergy Immunol 2016;169(2):71-9.

25. Lake AM.Food-induced eosinophilic proctocolitis. J Pediatr Gastroenterol Nutr 2000;30 (Suppl):S58-60.

26. Lozinsky AC, Morais MB. Eosinophilic colitis in infants. J Pediatr (Rio J) 2014;90(1):16-21. 